\title{
The effects of strategic planning, purchasing strategy and strategic partnership on operational performance
}

\author{
Zeplin Jiwa Husada Tarigan ${ }^{\mathrm{a}^{*}}$ and Hotlan Siagian ${ }^{\mathrm{b}}$
}

\begin{tabular}{l}
${ }^{a}$ Associate Professor of Master Managem \\
${ }^{b}$ Assistant Professor of Master Manage \\
\hline C H R O N I C L E \\
\hline Article history: \\
Received October 28, 2020 \\
Received in revised format \\
January, 15, 2021 \\
Accepted February 82021 \\
Available online \\
February 82021 \\
\hline Keywords: \\
Strategic planning \\
Purchasing \\
Partnership \\
Operational Performance
\end{tabular}

\section{Introduction}

One of the most significant current discussions in technology is the development of digital technology. This technology capitalization is possible in favor of internet technology, which enables the company to access much more information required in facing global competition. Globalization has made every company change the way in running its business system, including supply chain management practices. Supply chain management is defined as the management of the flow of goods and services that includes all value-added processes in turning raw materials into final products. The supply chain network covers all stages of the process from the supplier, production, distribution, retailer, and the end customer. Supply chain management also concerns the information system used in the network. The information system adoption by the company obviously enhances the company's competitive advantage through a cost reduction (Magutu et al., 2015). The role of technology facing globalization is essential, and it supports many companies' supply chain processes to win the competition (Qi et al., 2011). Recent studies have concerned the issue of how companies become more efficient and effective in running the business process. The strategic corporate can direct the organization's activities in building the supply chain capacity as a priority by leveraging the company's resources in the pursuit of a more efficient and effective business process (Ralston et al., 2015). The ability of the company's top management is highly required to implement strategic planning well in aligning the goals of the company with external opportunities and threats. This plan will provide the company's ability to develop strategies for the purchasing of raw materials, the company's operational strategy, and the * Corresponding author Tel.: +62312983145; Fax: +62 318436418

E-mail address: zeplin@petra.ac.id (Z. J. H. Tarigan)

C 2021 by the authors; licensee Growing Science. doi: $10.5267 /$ j.uscm.2021.2.006 
company's strategy for handling the distribution system and customer order handling. Effective strategic planning will enable the company to see the company's current strengths and weaknesses and determine the company's future goals based on its resources (Qi et al., 2011).

Supply chain strategic planning focuses on the company's external balance with the company's internal condition. The company always tries to adjust to the changes in customer's demand through a marketing strategy approach, and the company's suppliers through the purchasing strategy, and to the internal process through the operation strategy (Qi et al., 2017). The company's supply chain strategy correlates with the company's ability to build supply chain integration. Supply chain strategies are classified based on efficiency and responsiveness. Supply chain strategy related to responsiveness is the company's ability to control inventory levels in order to be able to provide the right response to customer requests. The responsiveness strategy must be accompanied by the appropriate level of efficiency so that the response given does not conflict with the efficiency that has been declared by the company (Birhanu et al., 2014).

The purpose of the supply chain strategy determined by the company to achieve rapid responsiveness in providing information to demand with an appropriate level of efficiency, it is necessary to develop strategic planning that fits that goal (Perez-Franco et al., .2016). Supply chain strategy is the advantage of the supply chain of the company compared to its competitors in fulfilling the market demand with the company's products based on the company's production capacity and the availability of raw materials from suppliers (Sharifi et al., 2013). The manufacturing company sets the plan by setting the final goal of each company. Strategic planning for companies correlates with the ability of personnel in the company to work effectively and to achieve company goals set by the management (Aldehayyat \& Khattab, 2013).

Furthermore, the company's strategic planning determines the marketing strategy, operational strategy, purchasing strategy, strategic planning, strategic partnership with external parties in achieving the specified supply chain strategy (Ralston et al., 2015). The strategic planning is established to anticipate the occurrence of uncertainty and inaccuracy in predicting the demand for each company's products, thus determining the accuracy of purchasing of raw materials, the accuracy of manufacturing results on the production floor so that the company needs to place inventory at a certain level in order to be able to maintain rapid responsiveness and high-efficiency (Piprani et al., 2020). Besides, the company calculates the right amount of inventory in maintaining a balance between the uncertainty of demand for the company's finished products and the uncertainty in the purchasing of raw materials (Tarigan, 2018). In line with the previous research, the strategic planning process is starting from the market strategy by establishing the existing market or new market. Data from the market strategy will move to determine the product strategy related to the existing product or new product, then communicated within the company to determine the supply chain strategy through product configuration and company operational strategy (Sharifi et al., 2013).

The corporate strategic planning will determine a strategy formulation with the company's strategy implementation by estimating the company's material purchasing strategy in meeting product order demands (Amrollahi and Rowlands, 2017). Besides, the ability of the company to maintain the balance of demand with certain product functions with stable raw material purchasing, the strategy set by the company is the efficient supply chain, and vice versa, if the product demand from customers is related to new products and stable company suppliers, the right strategy used by the company, is responsive supply chain (Birhanu et al., 2014). Also, manufacturing companies tend to build competitiveness in producing existing products with functions that are used by customers on an ongoing basis and new products produced by companies with stable suppliers to maintain the sustainability of production by building long-term partnerships with suppliers (Ghadimi et al., 2018).

Purchasing strategies in the company require appropriate strategic planning so that it plays a role in the purchasing department to build the right strategic partnership with the company's suppliers. The purchasing strategy set by the company at a textile company in Hong Kong has an impact on improving company performance (Yuen \& Cheng, 2013). Strategic partnerships between companies and suppliers are an ongoing reciprocal relationship that involves a commitment over a long period and sharing information and risks and rewards from the relationship. The purchasing strategy of the company selects the suppliers by comparing it with one another, then the company determines according to the criteria set by the company. Alternatively, the company can reduce transaction costs by building good synergies with suppliers through collaboration built with a small number of suppliers (Yoon \& Moon, 2019).

Other researchers found that the strategic partnership the company builds with suppliers depends on the culture of the company and also the purchasing strategy established by the company in achieving the company's goals (Cao et al., 2015). The strategic partnership with suppliers aims to improve the quality particularly, reduce costs, maintain material supply stability, share the information, build open communication between the two parties, and share the risks and reward within a specified period. The strategic partnership provides an impact on purchasing strategy in terms of raw material purchasing. Partnerships, therefore, are essential in the pursuit of sustainable materials supply at an affordable price. The company can achieve an excellent level of efficiency and responsiveness simultaneously in fulfilling customer demand. The company's ability to build win-win partnerships with suppliers enables the two parties to reduce purchasing costs (Yoon \& Moon, 
2019; Ghadimi et al., 2018)). Besides, a better level of strategic partnership can provide improved performance of manufacturing companies (Paulraj et al., 2006).

Moreover, the company's product development strategy determines whether it is necessary to modify existing products or make new products (Sharifi et al., 2013). The specified product development strategy will determine the way of purchasing strategy in terms of supplier selection, the establishment of the contracts with suppliers, and the development of relationships with suppliers. As has been noticed, the strategy developed by the company aims to improve its competitiveness to outperform the competitor and enhance the operational performance throughout the existing products or new products.

It should be noted from the above discussion that most studies have examined the impact of strategic planning, purchasing strategy, and strategic partnership in improving operational performance. However, to the best of authors' knowledge, there has been no research dealing with the impact of those constructs on operational performance simultaneously. Therefore, this study aims to empirically investigate the impact of strategic planning, purchasing strategy, strategic partnership, on operational performance simultaneously. This study has three broad objectives; first, to get the role of strategic planning, purchasing strategy, and strategic partnership in improving the performance of manufacturing companies. Second, the extent to which the purchasing strategy influences strategic partnership and operational performance. Third, to find the extent to which the strategic partnership affects the performance of manufacturing companies.

\section{Literature Review of Supply Chain Management}

The ability of companies to plan and determine corporate strategy dictates other strategies of the business functions in improving their competitiveness compared to the competitors. The corporate strategy enhances the company's competitiveness in the long term and on an ongoing basis. Supply chain strategy defines the extent to which the firm fulfills the customer demand measured in terms of cost, responsiveness, speed of delivery, and flexibility (Perez-Franco et al., .2016). The corporate strategy provides a guide in building the marketing strategies related to customer demand, operational strategies in developing the internal capabilities, and the purchasing strategy in procuring raw materials (Qi et al., 2011). Besides, the operational performance of a manufacturing company is defined as an organization's ability to produce and deliver products with a level of efficiency and quality in fulfilling the market demands within a shorter time, and at the end, increase the market share (Younis et al., 2016).

\subsection{Strategic Planning}

Strategic planning is an effort made by the company in a disciplined and systematic way to build interactions with related functions in setting decisions as a guideline for corporate objectives within a specified period to maintain and enhance the company's competitiveness towards its business environment (Suklev \& Debarliev, 2012; Amrollahi and Rowlands, 2017). Another research states that strategic planning is an effort to adjust the company's internal strengths and weaknesses relative to the company's external environment (Mosoti \& Murabu, 2014). Besides, strategic planning is considered critical for companies to develop a longer organizational life cycle and to create competitiveness (Abosede et al., 2016). Also, strategic planning is defined as the company's system capability in assessing the company's internal capability by taking into account the company's external conditions in planning the resources. The company also evaluates external companies related to trends in the corporate environment. The external and internal conditions need to be balanced by the company by using specific techniques to formulate the strategy. The result of the analysis establishes the corporate strategy, which integrated all the company's functions in the pursuit of synergistic in achieving company goals (Aldehayyat \& Khattab, 2013). Indicators used to measure strategic planning are cross-functional involvement, involving partners in making planning, final planning decision socialization to all internal functions, planning involving the internal cross-function, partners can access planning final result, and planning can be revised again.

\subsection{Purchasing Strategy}

The purchasing strategy is a process of "planning, implementing, evaluating, and controlling the purchasing decisions to direct all activities of the purchasing function towards opportunities that are consistent with the company's ability to achieve its long-term goals. Purchasing strategies in the company can be divided into strategic focus, strategic involvement, and strategic visibility (Paulraj et al., 2006). The purchasing strategy is a way how the manufacturing companies determine the purchasing of materials needed by the company by communicating, coordinating, and collaborating with suppliers. The company seeks to conduct a transaction to enhance the involvement of more suppliers in the pursuit of a lower cost of raw materials, higher product quality, and participation of the supplier in product innovations to compete in the market (Laari et al., 2017).

Changes in the customer demand, such as better quality and shorter life cycles, have resulted in changes in the purchasing strategy, such as controlling the fixed costs and considering all aspects that can reduce the cost and improvement in quality (Yuen and Chang, 2013). Purchasing strategy in a company is determined by the organizational dimension between mechanistic and organic, where the organic structure will support innovation strategy with low centralization 
characteristics, which means decentralization and low organizational function but a tremendous cross-functional role. Purchasing strategy with high structure mechanistic with low cross-functional involvement so that the company supports the cost strategy by implementing low cost (Ateş et al., 2018). Tarigan et al., (2020) state that purchasing strategy measurement items estimate potential suppliers enter into contracts with suppliers, have long-term partnerships with suppliers, and carry out continuous evaluations.

\subsection{Strategic Partnership}

A successful strategic partnership involves a high level of trust, commitment, coordination, and interdependence. Building strategic partnerships require organizational compatibility and top management's congruence with the partners' organization. Strategic partnerships deal with long-term relationships that focus on strategic goals aiming at providing value to customers and profitability to partners. A strategic partnership is a relationship formed between two independent entities in the supply chain to achieve specific goals and benefits, and provide a competitive advantage and improve financial performance to partners. Through the strategic partnership, both parties will be able to accurately predict raw material requirements in fulfilling the customer demands (Chae et al., 2014). Furthermore, the strategic partnership will help companies anticipate demand uncertainty, supply uncertainty, and technology development uncertainty (Qi et al., 2011). The strategic partnership will enable the enterprise and supplier to solve the constraints faced by the supplier in obtaining information, providing raw materials, and achieving the targeted product delivery times (Jajja et al., 2019). In summary, strategic partnerships between the manufacturing and the supplier will provide many positive results, including responsive improvements, guaranteed product availability, optimized inventory with associated costs, and increased revenue.

\subsection{Operational performance}

The company's capability to grow or develop depends on whether the company is capable of configuring and building an excellent network following market demand and product configuration strategy set. Supply chain performance has two dimensions, namely competitive performance and operational performance (Alzoubi and Yanamandra, 2020). The company's product strategy adjusts with the market demand in terms of modifying existing products, developing new or hybrid of the two choices (Sharifi et al., 2013). The specified product strategy will determine the configuration of material purchasing by conducting supplier selection, making contracts with suppliers, and establishing relationships with suppliers as a form of purchasing strategy (Tarigan, 2020). The company seeks to improve business performance by measuring, among others, on return on investment (ROI), return on assets (ROA), market share, growth in ROA, growth in ROI, and growth in market share (Qi et al., 2011, Beheshti et al., 2014). Younis et al., (2016) state that corporate performance is measured from four dimensions: firstly environmental performance with indicators of reducing production waste and saving on the use of company resources, secondly operational performance with indicators of increasing company efficiency and product quality improvement, third is the economic performance with indicators of profitability and returns improvement a positive share value, and finally the fourth is a social performance with indicators of increasing employee job satisfaction and improving employee health and safety. Competitive advantage factors likely cost, quality, delivery time, flexibility and creativity or innovation (Khaddam et al., 2020).

\subsection{Relationship between Concepts Variable and Hypotheses Development}

Strategic planning, an effort to adjust the company's internal to the company's external, is needed when making a purchasing strategy (Mosoti \& Murabu, 2014). Strategic planning needs to focus on the supply chain integration in order for the internal functions to coordinate quickly so that the purchasing department can determine the favorable specific purchasing strategy. Companies can also integrate with external parties, namely, integration with suppliers and integration with customers. Integration with suppliers makes it easy for companies to conduct capacity planning, forecasting, production planning, and product delivery (Piprani et al., 2020).

The strategic planning set by the company will focus on adjusting internal conditions to external conditions by formulating the corporate strategy and implementing the strategy consistently in real-time. Strategic planning will build a strategic partnership by maintaining a long-term relationship with the hope that company outcomes can be achieved (Amrollahi \& Rowlands, 2017). A strategic partnership is a relationship formed between two independent entities in the supply chain to achieve specific goals and benefits and provide competitive advantages and improve performance to partners. Partnerships that are built by companies with external parties in the supply chain flow will be open to one another in understanding the mission, business strategy, company goals so that they collaborate in planning strategies together with partners (Orr and Jadhav, 2018). Based on this description, the following second hypotheses can be made:

\section{$\mathrm{H}_{1}$ : Strategic planning influences purchasing strategy. \\ $\mathrm{H}_{2}$ : Strategic planning influences strategic partnership.}

The companies involve suppliers in corporate strategic planning so that both parties can collaborate in the planning stage to improve the performance of manufacturing companies (Orr \& Jadhav, 2018). In addition, companies adopting strategic 
planning allocate resources following the requirement in the manner of more efficient usage of raw material to improve the company's performance (Yuen \& Thai 2017). Furthermore, strategic planning conducts joint planning with suppliers as an external part becomes an essential activity in anticipating and solving operational problems in the pursuit of increasing the company's operational performance (Beheshti et al., 2014). The above argument leads to the following third hypothesis:

\section{$\mathrm{H}_{3}$ : Strategic planning influences operational performance.}

A strong strategic partnership between a company as a buyer and its suppliers is a form of purchasing strategy that the company uses to support company flexibility (Yang et al., 2019). The purchasing strategy of a company capable of building a long-term partnership with its suppliers will create new business opportunities by increasing the volume of transactions. The purchasing strategy enables the integration of the company's operations with its suppliers as partners (Jajja et al., 2019). Cao et al., (2015) stated that the collaboration with suppliers allows the integration between the external and internal business process to result in an efficient and effective product flow during the value-added stages of the company. Based on the above discussion, the fourth hypothesis is proposed as follows:

\section{$\mathrm{H}_{4}$ : Purchasing strategy influences strategic partnership.}

Purchasing strategy by adopting the outsourcing strategy to the suppliers, namely the company's internal activities in making products transferred to external parties, is able to provide increased company flexibility, effectiveness, and efficiency (Bals \& Turkulainen, 2017; Tarigan, 2019). Deviations from the ideal structure of centralized purchasing with a formal structure and cross-functional results in a decline in corporate performance (Ateş et al., 2018). Strategic partnership and supplier involvement in the purchasing and production process can have an impact on company performance in reducing production costs and increasing company profits (Beheshti et al., 2014; Tarigan, 2018). Based on the above argument, the fifth hypothesis is formulated as follow:

\section{$\mathrm{H}_{5}$ : Purchasing strategy has a significant effect on operational performance.}

The long-term relationship between the company as a buyer and its suppliers in building partnerships will have an impact on the company's operational strategy to improve manufacturing financial performance by adopting environmental and social sustainability (Ghadimi et al., 2018). A corporate, having a good relationship with its suppliers, has a responsibility in developing its suppliers on how to become more efficient and effective in enhancing the company's performance on an ongoing basis (Orr \& Jadhav, 2018; Yuen \& Thai 2017). The buyer-supplier relationship as a form of partnership provides strength in collaborating, information sharing, high flexibility, which will result in an impact on improving company performance, especially in marketing strategies (Yang et al., 2019). The ability of companies to partner with suppliers in order to implement supplier integration provides a significant increase in cost efficiency, customer service performance, performance, and flexibility performance (Piprani et al., 2020). Based on the above explanation, the following research hypothesis is determined.

\section{$\mathrm{H}_{6}$ : Strategic partnership influences the operational performance.}

\section{Research method}

The population of this study is manufacturing companies located in the region of East Java, Indonesia. Based on the data retrieved from the east Java Bureau of statistics indicated that 170 companies are covering the medium and large size, which are characterized by the number of employees, at least 20 employees. The second criterion for the sample is that the companies have established partnerships between manufacturing companies and their suppliers. This study surveyed those 170 companies using a questionnaire designed with a five-point Likert scale. Data collection is performed through cooperation with the student from the institution by using the grants to fund the expenses for the data collection. Of the 170, 153 questionnaires have been returned to the team while the rest are not returned until the time limit. Before data analysis, data cleaning was performed to make sure that all data are valid. However, of the 153, only 135 questionnaires are considered valid while the rest are not completed correctly. Furtherly, valid data are analyzed to assess the validity and reliability of the measurement model before continuing to examine the six hypotheses developed. Data analysis used the partial least square (PLS) technique utilizing the smart PLS software version 3.0. Fig. 1. demonstrates the distribution of the respondents in terms of work experiences.

As shown in Fig. 1, the highest number of respondents corresponds to the working experience for more than ten years $(27.4 \%)$. This result also indicates that around $80 \%$ respondent has working experience of more than three years. This finding indicated that respondents considered knowledgeable about the company and capable of responding to the questionnaire without any bias. Also, the figure shows that, as many as $47 \%$ of companies are employing more than 200 employees, which means the respondents represented the medium and large size of manufacturing companies. This result also demonstrates that most of the companies have been practicing the constructs of this study. 


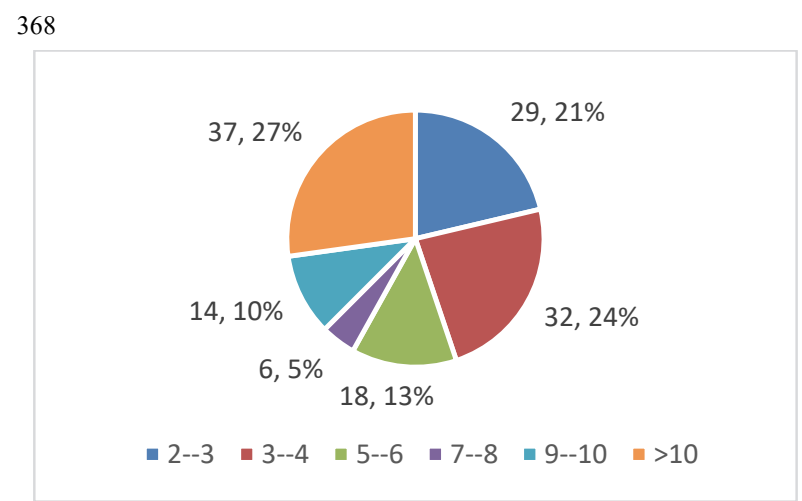

Distribution of respondent working experiences

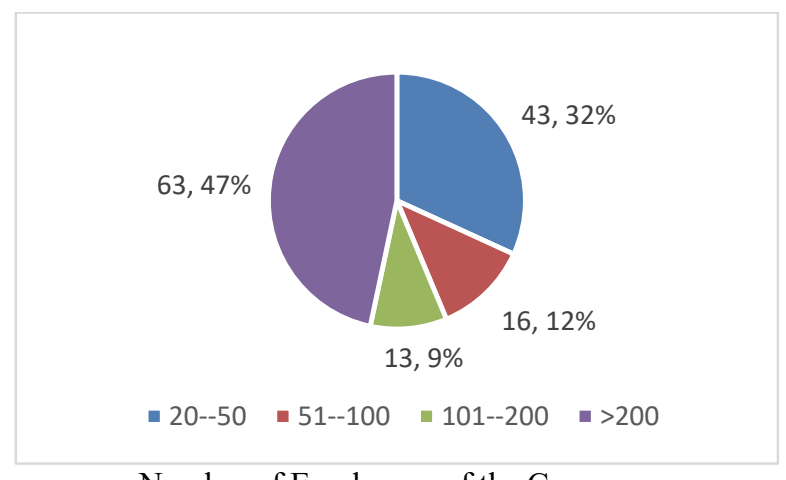

Number of Employees of the Company

Fig. 1. Personal information of the participants

As has been described before, this study involves operational performance as the dependent variable, strategic planning as an independent variable, purchasing strategy, and strategic partnership as a mediating variable. Strategic planning is measured using six indicators, which is Stra. Plan1 (involves cross-functional planning), Stra. Plan2 (involving partners in making plans), Stra. Plan3 (final planning is socialized to all internal functions), Stra. Plan4 (planning can be crossfunctional internal), Stra. Plan5 (partners can access planning), and Stra. Plan6 (predetermined planning can be revised again). The purchasing strategy is assessed using four indicators, which are Stra. Purch1 (purchasing strategy is part of the corporate strategy), Stra. Purch2 conducts supplier evaluations periodically, Stra. Purch3 purchasing strategy is a reflection of market demand, Stra. Purch4 (companies estimate the ability of suppliers). This measurement adopted the previous research (Paulraj et al., 2006; Tarigan et al., 2020, Tarigan et al., 2019; Ateş et al., 2018). The third construct, strategic partnership, adopted the five indicators previously used by (Qi et al., 2017, Tarigan et al., 2020; Yuen and Thai 2017), namely, Stra. Parth1 (sharing information with suppliers), Stra. Parth2 (long-term relationship with suppliers), Stra. Parth3 (collaboration with suppliers), Stra. Parth4 (involvement supplier for the company), Stra. Parth5 (renew contracts with suppliers periodically). The last construct, manufacturing performance assessed by using four indicators, adopted from the previous research (Yuen \& Thai, 2017; Tarigan, 2018; Chae et al., 2014; Tarigan et al., 2019), which are Operates. Perf1 (fulfillment customer order), Operate. Perf2 (product customization), Operat. Perf3 (product quality), Operat. Perf4 (total cost reduction).

\section{Analysis and Discussion}

The first step of analysis is to assess the measurement model to make the indicators are valid and reliable. An indicator is considered valid when the factor loading value exceeds 0.5 , and the cross-loading is less than the factor loading. While an indicator is considered reliable when the composite reliability and the Cronbach" s alpha value is higher than 0.70 (Hair et al., 2014). The measurement model is assessed using the PLS technique by utilizing the smartPLS software.

\section{Tabel 1}

Measurement assessment for variable and indicators of research

\begin{tabular}{|c|c|c|c|}
\hline Item Measurement & Loading Factor & Mean & Standard Deviation \\
\hline \multicolumn{4}{|l|}{ Strategy Planning (Reliability $=0.858)$} \\
\hline Stra. Plan1 (involvement of cross functional planning) & 0.714 & 4.1407 & 0.7347 \\
\hline Stra. Plan2 (involving partners in making plans) & 0.686 & 4.2074 & 0.6813 \\
\hline Stra. Plan3 (final planning is socialized to all internal functions) & 0.698 & 4.0667 & 0.7649 \\
\hline Stra. Plan4 (planning can be cross functional internal) & 0.594 & 3.9778 & 0.7961 \\
\hline Stra. Plan5 (partners can access planning) & 0.765 & 4.2963 & 0.7026 \\
\hline Stra. Plan6 (predetermined planning can be revised again) & 0.781 & 4.1852 & 0.7549 \\
\hline \multicolumn{4}{|l|}{ Purchasing strategy $($ Reliability $=0.868)$} \\
\hline Stra. Purch1 (purchasing strategy is part of a corporate strategy) & 0.858 & 4.0000 & 0.7124 \\
\hline Stra. Purch2 (periodically evaluating suppliers) & 0.809 & 4.1407 & 0.7141 \\
\hline Stra. Purch3 (purchasing strategy is a reflection of market demand) & 0.797 & 4.1926 & 0.7175 \\
\hline Stra. Purch4 (company develop supplier capability) & 0.686 & 4.2296 & 0.7425 \\
\hline \multicolumn{4}{|l|}{ Strategic Partnership $($ Reliability $=\mathbf{0 . 8 5 8})$} \\
\hline Stra. Parth1 (sharing information with suppliers) & 0.708 & 4.1259 & 0.7671 \\
\hline Stra. Parth2 (long-term relationship with suppliers) & 0.716 & 4.1778 & 0.5842 \\
\hline Stra. Parth3 (collaboration with supplier)) & 0.820 & 3.9852 & 0.7226 \\
\hline Stra. Parth4 (involvement of supplier) & 0.772 & 4.0148 & 0.6690 \\
\hline Stra. Parth5 (renew contracs with suppliers periodically) & 0.675 & 4.1704 & 0.6969 \\
\hline \multicolumn{4}{|l|}{ Operational Performance $($ Reliability $=\mathbf{0 . 8 5 3})$} \\
\hline Operates. Perf1 (fulfillment of customer orders) & 0.813 & 4.2296 & 0.7696 \\
\hline Operates. Perf2 (customization of product) & 0.754 & 4.1704 & 0.5800 \\
\hline Operates. Perf3 (quality of product) & 0.707 & 4.2593 & 0.6687 \\
\hline Operates. Perf4 (total cost reduction) & 0.800 & 4.2296 & 0.6685 \\
\hline
\end{tabular}


Table 1 shows that, in all cases, the factor loading is greater than 0.50 , which means that all indicators are valid. Those indicators of the strategic planning values between 0.594 to 0.781 (higher than 0.50 ). The factor loading for the purchasing strategy values between 0.686 to 0.858 . Similarly, factor loading for strategic partnership is between 0.675 and 0.820 . Lastly, the operational performance has the factor loading value between 0.707 and 0.813 . As also shown in Table 3 , all the constructs have a reliability value higher than 0.70 (in all cases between 0.853 and 0.868 ). Based on this result, the measurement model is considered valid and reliable, and further analysis is allowed. The subsequent analysis is to examine if the six hypotheses are supported or not. Table 4 demonstrated the result of the hypothesis testing. The value of the tstatistics in Table 2 determines if the hypothesis supported or not. For the significant level of 5\%, the corresponding $t$ value is 1.96. As shown in Table 2, those t-values are higher than 1.96, which means that the six hypotheses are empirically supported.

Table 2

Hypothesis testing result

\begin{tabular}{lcccc}
\multicolumn{1}{c}{ Research Hypothesis } & $\begin{array}{c}\text { The amount of } \\
\text { influence }\end{array}$ & $\begin{array}{c}\text { Standard } \\
\text { Deviation }\end{array}$ & T-Statistics & Hypothesis \\
\hline Strategic planning $\rightarrow$ Purchasing Strategy (H1) & 726 & 41 & 17.618 & Supported \\
\hline Strategic planning $\rightarrow$ Strategic partnership (H2) & 669 & 65 & 10.313 & Supported \\
Strategic planning $\rightarrow$ Operational Performance (H3) & 0.286 & 0.13 & 2.195 & Supported \\
Purchasing Strategy $\rightarrow$ Strategic partnership (H4) & 0.135 & 0.068 & 1,967 & Supported \\
Purchasing Strategy $\rightarrow$ Operational Performance (H5) & 0.142 & 0.081 & 2,017 & Supported \\
Strategic partnership $\rightarrow$ Operational Performance (H6) & 0.252 & 0.104 & 2,436 & Supported \\
\hline
\end{tabular}

Table 2 highlights that all six hypotheses (H1-H6) are empirically supported. All the t-statistic value is greater than 1.96 for a significant level of 5\% (in all cases between 1.967 and 17.618). The first hypothesis, strategic planning, influences the purchasing strategy, is supported by the data. These results indicate that when both parties have a mutual strategic plan in terms of accessibility to the plan, and flexibility of the plan following external changes, both parties are allowed to revise the purchasing strategy. The result also shows that manufacturing companies can periodically evaluate suppliers according to the performance achieved and revise the strategy if necessary. This finding supports the previous study by Mosoti \& Murabu (2014), which stated that the strategic planning needs to focus on the supply chain integration in order for the internal functions to coordinate quickly so that the purchasing department can determine the favorable specific purchasing strategy.

Table 2 also demonstrates that the second hypothesis, strategic planning, affects the strategic partnership, is accepted. This finding is in line with the result by Amrollahi and Rowlands, (2017) and Orr and Jadhav, (2018). Strategic planning improves strategic partnership. The company which has adopted a strategic planning approach in terms of involvement of partners in doing planning, and partners can access the plan, will be able to adjust the strategic partnership in terms of responsiveness improvements, product availability, optimized inventory with associated costs, and increased revenue. The company's ability to plan internal needs through the cross-functional within the company will improve its strategic partnership through stronger collaboration with suppliers. The collaboration will benefit the company and suppliers together when the supplier can adjust the changes that occur in manufacturing companies quickly.

Furthermore, the result also shows that the third hypothesis, strategic planning, influence the operational performance, is empirically supported. Strategic planning, which is defined as the extent to which the company collaborates with suppliers, will directly affect the operational performance in terms of fulfillment of demand, customization of the product, improved quality of the product, and reduced total cost. Strategic planning is highly essential in enhancing the performance of the company. This finding is consistent with the study by Orr and Jadhav, (2018), Yuen and Thai, (2017), and Beheshti et al., (2014). Those studies concluded that the existence of strategic planning is vital in improving the performance and the competitiveness of the company. As an illustration, the manufacturing company adopting a strategic planning approach involves cross-functional teamwork in cooperation with suppliers. When the supplier can review the plan and, together with the company, revise the plan, the collaboration will benefit the company in terms of the ability to meet customer demand. Table 4 also proved that a purchasing strategy influences the strategic partnership (fourth hypothesis). The purchasing strategy determined and adjusted to the corporate strategy can increase the company's level of strategic partnership in terms of collaboration on processes and product development. The strategic partnership relies on suppliers' capability in supplying stable raw materials, establishing long-term cooperation, and sharing information dictate the success of the purchasing strategy. This finding correlated with previous research by Bals and Turkulainen, (2017), Tarigan, (2019), Ateş et al., (2018), Beheshti et al., (2014), Tarigan, (2018), which suggested that purchasing strategy affect the strategic partnership.

The fifth hypothesis stated that purchasing strategy could improve operational performance. As Table 4 shows, the result supported this hypothesis. Company management always harmonizes corporate strategy with cross-functional strategies in all departments as well as purchasing strategy. The management also collaborates with suppliers by building an excellent 
relationship in the pursuit of reduced total operating costs and increased company capability in meeting customer orders. The company's management also builds long-term partnerships with suppliers through the renewal of contracts that have been established and extended periodically. This result supported the previous studies by Bals and Turkulainen, (2017), Tarigan, (2019), Ateş et al., (2018), Beheshti et al., (2014), Tarigan, (2018). Those studies suggested that purchasing strategy constitutes a vital approach in sourcing raw material and spare parts to ascertain the operation sustainability at a lower total cost.

The last hypothesis states that strategic partnership affects operational performance. The result of this study supported the hypothesis. This finding is consistent with research by Ghadimi et al., (2018), Orr and Jadhav (2018), Yuen and Thai (2017), Yang et al., (2019), and Piprani et al., (2020). The strategic partnership set by the company was able to improve the company's operational performance. This finding shows that the collaboration developed by the company and developing suppliers will increase the role of suppliers in the company's business processes. It will show an excellent innovation in the company's activities to make efficiency and effectiveness in reducing company operational costs and also improve the completion of production processes that have an impact on order fulfillment. Manufacturing companies in East Java, which carries out systematic strategic planning and involve the external companies, can build supply chain integration. The ability of manufacturing companies to engage suppliers in supply chain integration makes it easy for companies to build purchasing strategies and build partnership strategies to produce process innovations and product innovations to produce efficient, effective, and adaptability.

\section{Conclusion}

This study set out to determine the influence of strategic planning, purchasing strategy, strategic partnership, on operational performance. The following conclusions were obtained. 1) Strategic planning influences purchasing strategy, 2) Strategic planning influences strategic partnership, 3) Strategic planning influences operational performance, 4) Purchasing strategy influences strategic partnership, 5) Purchasing strategy has a significant effect on operational performance, 6) Strategic partnership influences operational performance. This study highlights that the strategic planning set by the company is needed to maintain a balance in the company's supply chain flow to achieve efficiency, effectiveness, and adaptability. Strategic planning should adjust to the vision and goals set by the company's management. Strategic planning, which involves the company's internal and external parties, influences the company's purchasing strategy, strategic partnership, and operational performance. A purchasing strategy enables the company to match the suppliers with the demand. The company's ability to coordinate and collaborate with suppliers through sharing information and involving suppliers in process innovation and product innovation, improve operational performance by reducing total production costs and the company's ability to meet customer demand. This result provides an insight for the practitioner on how to improve the operational performance by adopting an approach of strategic planning, purchasing strategy, and strategic partnership. This research also contributes to the ongoing research in the field of supply chain management theory.

\section{Acknowledgments}

Authors would like to thank DRPM and Higher Education Indonesia for providing the post graduate grant in funding this research [B/87/E3/RA.00/2020]

\section{References}

Abosede, A.J., Obasan, K.A., \& Alese, O.J. (2016). Strategic management and small and medium enterprises (SMEs) development: A review of the literature. International Review of Management and Business Research, 5(1), 315-335.

Aldehayyat, J. \& Khattab, A.A. (2013). Strategic planning and organisational effectiveness in Jordanian hotels. International Journal of Business and Management, 8(1),11-25, DOI:10.5539/ijbm.v8n1p11

Alzoubi, H.M. \& Yanamandra, R. (2020). Investigating the mediating role of information sharing strategy on agile supply chain. Uncertain Supply Chain Management, 8(2), 273-284, doi: 10.5267/j.uscm.2019.12.004

Amrollahi, A. \& Rowlands, B. (2017). Collaborative open strategic planning: a method and case study. Information Technology \& People, 30(4), 832-852. https://doi.org/10.1108/ITP-12-2015-0310

Ateş, M.A., Raaij, E.M.V., \& Wynstra, F. (2018). The impact of purchasing strategy-structure (mis)fit on purchasing cost and innovation performance. Journal of Purchasing and Supply Management, 24(1), 68-82, https://doi.org/10.1016/j.pursup.2017.05.002

Beheshti, H.M., Oghazi, P., Mostaghel, R., \& Hultman, M. (2014). Supply chain integration and firm performance: an empirical study of Swedish manufacturing firms. Competitiveness Review, 24(1), 20-31, DOI 10.1108/CR-06-20130060

Bals, L., \& Turkulainen, V. (2017). Achieving efficiency and effectiveness in Purchasing and Supply Management: Organization design and outsourcing. Journal of Purchasing and Supply Management, 23(4),256-267, https://doi.org/10.1016/j.pursup.2017.06.003

Birhanu, D., Lanka, K., \& Rao, A.N. (2014). A survey of classifications in supply chain strategies. Procedia Engineering, 97, 2289 - 2297, doi: 10.1016/j.proeng.2014.12.473 
Cao, Z., Huo, B., Li, Y. \& Zhao, X. (2015). The impact of organizational culture on supply chain integration: a contingency and configuration approach. Supply Chain Management, 20(1), 24-41. https://doi.org/10.1108/SCM-11-2013-0426

Chae, B.K., Yang, C., Olson, D., \& Sheu, C. (2014). The impact of advanced analytics and data accuracy on operational performance: A contingent resources-based theory (RBT) perspective. Decision Support Systems, 59, 119-126, https://doi.org/10.1016/j.dss.2013.10.012

Chiang, N.Y., Lin, Y., \& Long, Q. (2020). Efficient propagation of uncertainties in manufacturing supply chains: Time buckets, L-leap, and multilevel Monte Carlo methods. Operations Research Perspectives, 7, 1-15, 100144, https://doi.org/10.1016/j.orp.2020.100144

Ghadimi, P., Toosi, F.G., \& Heavey, C., (2018). A multi-agent systems approach for sustainable supplier selection and order allocation in a partnership supply chain. European Journal of Operational Research, 269(1), 286-301. doi: 10.1016/j.ejor.2017.07.014

Jajja, M.S.S., Asif, M., Mantabon, F., \& Chatha, K.A. (2019). Buyer-supplier relationships and organizational values in supplier social compliance. Journal of Cleaner Production, 214, 331-344, https://doi.org/10.1016/j.jclepro.2018.12.289

Khaddam, A.A., Irtaimeh, H.J., \& Bader, B.S. (2020). The effect of supply chain management on competitive advantage: The mediating role of information technology). Uncertain Supply Chain Management, 8(3), 547-562, doi: $10.5267 /$ j.uscm.2020.3.001

Laari, S., Töyli, J., \& Ojala, L. (2017). Supply chain perspective on competitive strategies and green supply chain management strategies. Journal of Cleaner Production, 141, 1303-1315, https://doi.org/10.1016/j.jclepro.2016.09.114

Magutua, P.O., Aduda, J., \& Nyaoga, R.B. (2015). Does supply chain technology moderate the relationship between supply chain strategies and firm performance? evidence from large-scale manufacturing firms in Kenya. International Strategic Management Review, 3, 43-65, http://dx.doi.org/10.1016/j.ism.2015.07.002

Mosoti, Z., \& Murabu, E.K. (2014). Assessing the implication of strategic planning on the performance of small-sized organizations: A case study of small enterprises in Thika town. Journal of Research in Business and Management, 2(3), $1-13$.

Paulraj, A., Chen, I. J., \& Flynn, J. (2006). Levels of strategic purchasing: impact on supply integration and performance. Journal of Purchasing and Supply management, 12(3), 107-122., DOI:10.1016/j.pursup.2006.08.002

Piprani, A.Z., Mohezar, S., \& Jaafar, N.I. (2020). Supply Chain Integration and Supply Chain Performance: The Mediating Role of Supply Chain Resilience. International Journal of Supply Chain Management, 9(3), 58-72.

Qi, Y., Huo, B., Wang, Z., \& Yeung, H.Y.J. (2017). The impact of operations and supply chain strategies on integration and performance. International Journal of Production Economics, 185, 162-174, http://dx.doi.org/10.1016/j.ijpe.2016.12.028

Qi, Y., Zhao, X., \& Sheu, C., (2011). The impact of competitive strategy and supply chain strategy on business performance: the role of environmental uncertainty. Decision Sciences, 42(2), 378-389, doi.org/10.1111/j.1540-5915.2011.00315.x

Ralston, P.M., Blackhurst, J., Cantor, D.E. \& Crum, M.R. (2015). A structure-conduct- performance perspective of how strategic supply chain integration affects firm performance. Journal of Supply Chain Management, 51(2), 47-64, DOI: 10.1111/jscm.12064

Sharifi, H., Ismail, HS, Qiu, J., \& Tavani, S.N. (2013). Supply chain strategy and its impacts on product and market growth strategies: A case study of SMEs. International Journal of Production Economics, 45(1), 397-408, https://doi.org/10.1016/j.ijpe.2013.05.005

Skokan, K., Pawliczek, A., \& Piszczur, R. (2013). Strategic planning and business performance of micro, small, and medium-sized enterprises. Journal of Competitiveness, 5(4), 57-72, DOI: 10.7441/joc.2013.04.04

Suklev, B., \& Debarliev, S. (2012). Strategic planning effectiveness comparative analysis of the Macedonian context. Economic and Business Review, 14(1), 63-93

Tarigan, Z.J.H. (2018). The impact of organization commitment to process and product innovation in improving operational performance. International Journal of Business and Society, 19(2), 335-346

Tarigan, Z.J.H., Siagian, H., Basana, S.R., \& Jie, F. (2019). Effect of Key User Empowerment, Purchasing Strategy, Process Integration, Production System to Operational Performance. E3S Web of Conferences, 130, 01042, https://doi.org/10.1051/e3sconf/201913001042

Tarigan, Z.J.H., Siagian, H., \& Jie, F. (2020). The role of top management commitment to enhancing the competitive advantage through ERP integration and purchasing strategy. International Journal of Enterprise Information Systems, 16(1), DOI: 10.4018 / IJEIS.202001010

Yang, Z., Jiang, Y., \& Xie, E. (2019). Buyer-supplier relational strength and buying firm's marketing capability: An outsidein perspective. Industrial Marketing Management, 82, 27-37, https://doi.org/10.1016/j.indmarman.2019.03.009.

Yoon, J., \& Moon J. (2019). The moderating effect of buyer purchasing strategy on the relationship between supplier transaction-specific investment and supplier firm performance. Journal of Business Research, 99, 516-523, https://doi.org/10.1016/j.jbusres.2017.08.022

Younis, H., Sundarakani, B., \& Vel, P. (2016). The impact of implementing green supply chain management practices on corporate performance. Competitiveness Review, 26(3), 216-245, DOI 10.1108/CR-04-2015-0024

Yuen, S.S.M. \& Cheng, C. (2013). Purchasing strategy in Textile and Apparel Sourcing Companies in Hong Kong: A Practitioner's Perspective. Journal of Business and Economics, 4(11), 1148-1158.

Yuen, K. F., \& Van Thai, V. (2017). The influence of supply chain integration on operational performance. The International Journal of Logistics Management, 28(2), 444-463. DOI 10.1108/IJLM-12-2015-0241 
372

Yuen, K.F. \& Thai, V.V. (2017). The influence of supply chain integration on operational performance: A comparison between product and service supply chains. The International Journal of Logistics Management, 28(2), 444-463. https://doi.org/10.1108/IJLM-12-2015-0241

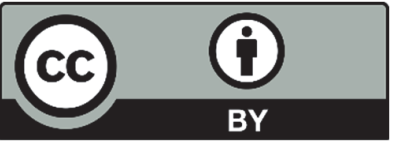

(C) 2021 by the authors; licensee Growing Science, Canada. This is an open access article distributed under the terms and conditions of the Creative Commons Attribution (CC-BY) license (http://creativecommons.org/licenses/by/4.0/). 